\title{
El «Entremés de la Buena Gloria» (1783) de Pedro García Diego. Estudio y edición
}

\author{
SALVADOR GARCÍA CASTAÑEDA \\ Ohio State University \\ Para Joaquín Sánchez Losada
}

La antigua costumbre de los mareantes santanderinos de celebrar la Buena Gloria acabó a fines del siglo XIX, desterrada por el progreso y perseguida por los anatemas de los moralistas. La costumbre se conoce por haber llegada hasta nosotros un Entremés de la Buena Gloria escrito y representado a fines del XVIII. Sin embargo, esta obra ni se ha impreso ni se ha difundido quizá por haberse juzgado de carácter popular e infraliterario, y probablamente también por el escaso aprecio que mostraron Amós de Escalante y Pereda, los primeros que se refirieron a ella.

He decidido editar el Entremés de la Buena Gloria pues, a mi juicio, es un texto de gran calidad costumbrista y además, parece ser la única obra de teatro con asunto local escrita en Cantabria en el siglo XVIII.

En sus Escenas montañesas (1864) describía Pereda una costumbre de las gentes de mar, todavía vigente entonces. Después de enterrar a un compañero, deudos y amigos acudían a casa de la recién viuda, donde se hacía una colecta para comprar algo de comer y sobre todo de beber, "a la buena gloria del difunto". Tales duelos solían acabar en gresca y Pereda, que llegó a conocerlos, los calificó de «es- 
candalosa provocación a la moral pública, al sentido común, a la sociedad entera» ${ }^{1}$.

Como curiosidad, y para probar la antigüedad de tal costumbre, incluía un pasaje del Entremés de la Buena Gloria, "manuscrito rancio y ahumado" de autor anónimo. La obra se dio en Santader el 30 de Agosto de 1783, el día de los Santos Mártires².

Pocos años más tarde, en 1873, publicó Amós de Escalante el artículo de costumbres "La montañesa", en el que se refería a este mismo sainete y daba varios fragmentos, aunque sin mencionar a Pere$\mathrm{da}^{3}$ : El texto que vio Escalante, también manuscrito, se titulaba Las buenas glorias de Baco y en la portada decía que se representó en marzo de 1783, con ocasión de los Carnavales. Daba como autor a don Pedro García Diego, "oficial mayor y vista de la real aduana" de Santander. A juzgar por los fragmentos que han llegado hasta nosotros de ambos manuscritos, las variantes son de menor cuantía ${ }^{4}$.

1. "La Buena Gloria», Escenas montañesas, en Obras Completas. Madrid, Aguilar, 1934, pp. 82-89. De esta «escena" se hizo una adaptación ilustrada tipo "comic» con ocasión del 150 aniversario del nacimiento de Pereda, La Buena Gloria, Santander, Gobierno de Cantabria, s.a. Con introducción de Benito Madariaga.

2. Ibid., pág. 86 .

3. "La Montañesa", capítulo del libro Las mujeres españolas, portuguesas y americanas tales como son en el hogar, etc. (Madrid, 1873) reimpreso luego en La Tertulia, pp. 4, $74,108,146,169,201$.

4. "Las Buenas Glorias de Baco, entremés nuevo que se representó en Santander con motivo de las diversiones de Carnaval, lunes 3 de Marzo de 1783. Dispuesto por don Pedro García Diego, oficial mayor y visto de la real aduana de dicho puerto. Un folleto manuscrito en $\mathbf{8 .}^{\circ}$, de cuarenta y cinco páginas útiles, seis de ellas de proemio, introducción o argumento. Fáltale el folio 41-42, rasgado. Teníalo en su librería mi respetable y ya difunto tío don Jusn Prieto Labat" (Obras escogidas, II. B.A.E., vol. 94, pág. 369, nota 21). García Diego nació en Espinosa de los Monteros, provincia de Burgos, en 1751 y fue personaje de relieve en la vida local del tiempo. Llegó a Intendente de la Provincia de Santander (1803) y luego a Contador de las de Burgos (1813) y Galicia (1814). La Junta Suprema de Cantabria le nKmbró Comisario de Guerra y Ministro de Hacienda de la plaza de Santander durante la guerra de la Independencia (véase Primera Guía de Santander publicada por D. Pedro García Diego. Edición facsímil. Con noticias biográficas del autor por D. Tomás Maza Solano. Santander, Bedia Hermanos, 1958). En las gestiones realizadas con el gobierno de Madrid para separar la provincia de Santander de la de Burgos contribuyó de modo efectivo con un memorial al ministro de Estado, en el que justificaba los motivos políticos y económicos de tal separación (véase José Luis Casado Soto, La Provincia de Cantabria. Notas sobre su constitución y ordenanzas (1727-1833). Santander, 1979, pág. 50 y nota 99). García Diego fue el primer Secretario que tuvo la Real Sociedad Cantábrica de Amigos del País y, además del entremés de La Buena Gloria, escribió el poema heroico de circunstancias Festivos júbilos... para celebrar el nombramiento del montañés don Pedro Ceballos Guerra como ministro de Estado, y una Primera Guía de Santander (1793), que fue el primer libro impreso en Cantabria y que luego editó Maza Solano. 
Debió de ser obra muy popular en su tiempo y que se pondría en escena en época de fiestas como lo indican las representaciones en los Carnavales, y en el día de los Mártires, abogados de la gente marinera. También parece que circuló mucho en forma manuscrita pues Pereda se refiere a un texto, con prólogo del autor y a "otras copias, que yo no he visto, del mismo entremés» ${ }^{5}$. Amós de Escalante usó de otra versión, prologada también, y en la Biblioteca Menéndez Pelayo de Santander, Sección de Fondos Modernos, en la Colección Pedraja, se conservan otras dos bajo las signaturas MS1221 y MS436.

Respecto a su antigüedad, Antón, uno de los personajes del entremés, da por muy sabido que la Buena Gloria venía desde sus tatarabuelos, y Justo, otro personaje, aseguraba que tuvo su origen en las Saturnales.

Después de citar la Iliada ( Consagremos nueve días a los llantos en las casas; el décimo encenderemos la hoguera, y se publicará por la ciudad el banquete fúnebre»), Lasaga Larreta escribe que cuando moría alguna persona de importancia entre los romanos se daba de comer al pueblo o se repartía un trozo de carne cruda, y que después de haber estado cerrada nueve días, se abría de nuevo la casa del difunto y los parientes se reunían para comer ${ }^{7}$.

En los primeros tiempos de la Iglesia y en días de fiesta tenían lugar unos ágapes llamados caridades que compartían pobres y ricos. Con el tiempo, estos convites se celebraron tan sólo en los funerales y Lasaga Larreta añade que la costumbre perduraba en su tiempo pues se llamaba caridades en los pueblos a la reunión que tenía lugar, después del entierro, en el atrio de la iglesia, donde se colocaba un crucifijo encima de una mesa. Allí se descubrían todos, se rezaba por el difunto y por sus parientes y luego, a intervalos, se servían tres vasos de vino a cada uno de los asistentes ${ }^{8}$.

5. Pereda, «La Buena Gloria», pág. 87, nota 1 .

6. MS 1221, sin prólogo, 18 folios, 34 pp.; MS 43, sin prólogo, 30 folios, 58 pp.

7. Gregorio Lasaga Larreta, «Un escrito inédito. Un entierro montañés-Las caridadesLuces-Ofrendas-Otros sufragios", Altamira, vol. 1-3 (dic. 1934), 181-192.

8. "Origen de la Robla y de la Buena Gloria», Dos memorias. Cuadros históricos y de costumbres antiguas de la Provincia de Santander (1899), reimpreso en Gregorio Lasaga Larreta, Antología de Escritores y Artistas Montañeses, vol. XXVI, Santander, 1952, pp. 101-111. 
El mismo autor escribía en 1902 que los únicos vestigios de esta costumbre eran ya los dos o tres vasos de vino que tomaban los pasiegos al volver de los entierros, a la puerta de la iglesia después de rezar por el alma del que había fallecido, y añadía que había visto también «a los pasiegos de las cabeceras de Selaya dar y tomar las caridades a la puerta de la taberna, rezando en medio de la cambera” ${ }^{9}$.

Los banquetes fúnebres dieron lugar a «desórdenes escandalosus" ya entre los primeros cristianos por lo que la autoridad eclesiástica procuró en todo tiempo combatir la costumbre. Lasaga Larreta cita una prohibición hecha a los cofrades del Rosario, de las Caldas, en el siglo XVII, de hacer tales convites "ni dar las bebidas que llamaban caridades" ${ }^{10}$, y Pablo de Gorosábal menciona una Real Provisión de 1771 que prohibía "convites, juegos ni concurso de gentes en la casa del difunto, ni a los sacerdotes que concurriesen a los entierros se les diese en ella de comer" ${ }^{11}$.

El primer obispo que tuvo Santander, don Francisco Javier de Arriaza (1755-1761) trató de acabar con la Buena Gloria y lo mismo hicieron sus sucesores además de los predicadores y los moralistas; y don Pedro García Diego, autor del sainete en cuestión, lo escribió con el propósito de «hacer irrisible este uso». Sin embargo perduraba en 1864 cuarido Pereda publicó las Escenas montañesas y aunque Amós de Escalante daba por desaparecida la costumbre en 1873, todavía dudaba Pereda en una nota a la edición de las Escenas de 1876, sin comprometerse a afirmar que "se ha desterrado enteramente».

La Buena Gloria es un sainete dieciochesco llamado todavía «entremés", aunque uno y otro no se diferencien en sustancia, y que, a juzgar por algunas referencias históricas en el texto, debió de escribirse poco antes de ser representado en 1783.

Por aquellos años estaba en su apogeo el sainete; recordaremos que entre 1786 y 1791 apareció, en vida del autor, la edición en diez volúmenes de los que llevaba escritos don Ramón de la Cruz, que en 1800 murió a los 37 años Juan Ignacio González del Castillo, quien llevó a las tablas las costumbres populares de Cádiz, y que también

9. «Un escrito inédito...", pág. 187.

10. Ibíd., pág. 187.

11. "De los entierros y funerales" en Noticias de las cosas memorables de Guipúzcoa... Tomo IV, Tolosa, Imprenta, Librería y Encuadernación de E. López, 1900, pp. 198-9. 
por entonces escribieron sainetes Manuel Fermín de Laviano, Comella, José López de Sedano y otros muchos. Para estudiar La Buena Gloria habrá que tener en cuenta lo que escribió Cotarelo refiriéndose a los sainetes de Cruz, en los que «vive y palpita una sociedad entera, hoy desaparecida, pero que, gracias a tales obras, podemos reconstruir casi con la misma verdad que si, por un milagro cronológico, retrocediéramos a la España del reinado de Carlos III» ${ }^{12}$.

La composición de nuestro entremés puede determinarse con bastante exactitud entre Enero de 1783 y Marzo del mismo año, cuando se representó en los Carnavales santanderinos. En el texto hay referencias a una guerra que es la de la Independencia norteamericana. En ella se enfrentó Inglaterra con su antigua colonia a la que ayudaron Francia y más tarde España (Junio 1779). Entre sus incidencias se recordarán la toma de Menorca, el sitio de Gibraltar y la ocupación de la Florida por los españoles. Gran Bretaña reconoció la independencia de los Estados Unidos en 1782 y, a poco, ingleses y franceses hicieron las paces (Enero 1783). Los españoles no aceptaron las considerables reclamaciones territoriales de sus adversarios pero, modificadas más tarde, Floridablanca hubo de aceptar la no devolución de Gibraltar y al fin se firmó la paz entre Inglaterra y España en Septiembre de aquel mismo año.

El ejemplo del movimiento independentista en el Norte y los abusos cometidos por los corregidores provocaron levantamiento en algunas colonias españolas y en 1780 hubo graves alzamientos de indios en el Perú encabezados por Tupac Amaru. La rebelión se extendió a Buenos Aires, donde adquirió grandes proporciones hasta que se logró la pacificación total mediado ya el año 83. Los pescadores tienen vagas noticias de estas cosas a través de parientes que sirven en los barcos del Rey destacados allí. La inquina que muestran estos pescadores contra los ingleses indica cuánto se hacía sentir la presencia de la marina británica en las costas del Cantábrico.

Desde el punto de vista estructural, a la acción propia del sainete antecede un cumplido diálogo entre el forastero Prudencio y su amigo santanderino Justo. Sirve de introducción o de marco y en él, aparte de las alabanzas a la ciudad propias de las loas, se explica lo

12. Emilio Cotarelo y Mori, Sainetes de Don Ramón de la Cruz en su mayoría inéditos, 2 tomos, NBAE. Vols. XXIII y XXXVI, Madrid, 1915 y 1928. "Discurso preliminar», vol. XXIII, pág. I. 
que son las reuniones de la Buena Gloria y Justo lleva a su amigo a presenciar una. La detallada acotación escénica indica la colocación de los personajes: los hombres reunidos a un lado, las mujeres con la viuda y unos niños a otro, mientras que Justo y Prudencio quedan entre bastidores.

A partir de entonces hablarán los hombres entre ellos y después las mujeres y asi alternativamente (siete veces unos y ocho las otras), con dos intervenciones de los dos amigos, al paño. La obra concluye a palos, final muy propio de entremés, con la reunión de todos los personajes, y de dos alcaldes de barrio que llegan a poner paz.

La introducción, a cargo de Justo y Prudencia, está en endecasílabos pareados, así como los primeros versos dichos por los hombres (vs. 1-76). Desde entonces la versificación, en romance é-o, no varía hasta llegar al desenlace moralizador cuando todos los personajes vuelven a expresarse en pareados endecasílabos (vs. 772-829).

El Entremés de la Buena Gloria tiene estructura primitiva, los personajes apenas se mueven y la acción brilla por su ausencia hasta muy cerca del final. Justo y Prudencio, a tenor de sus nombres, moralizan y lo hacen de manera pedantesca. En fin, la versificación peca de monótona y no es raro hallar versos ripiosos o a los que en ocasiones les falta o les sobra una sílaba.

Sin embargo la obra debió de gustar, y mucho, a un público local de todas las clases sociales al que posiblemente interesaba menos la intención reformadora del sainete que el contemplar puesta en solfa en las tablas la imagen viva y exacta de sus convecinos. En esto radican el interés -y la calidad-de una obrita que supo reflejar con gran acierto el modo de ser y de expresarse de un grupo social, "pintoresco» ya entonces para los demás santanderinos. García Diego era versificador mediocre y no sabía mover a sus personajes en escena, pero en cambio tenía grandes dotes para la observación y para expresar lo que veía. Prestó gran atención al color local y al indicar cómo se había de representar la obra escribía: «Se procurará imitar en cuanto se pueda el tono de habla, acciones y gestos que se ven comúnmente en esta clase de mujeres, pues en esto consiste la gracia del Entremés».

Estas líneas indican que para entonces el personaje de la pescadora era ya un tipo costumbrista, y que, para su autor, la gracia del 
entremés era principalmente verbal ${ }^{13}$. Este carecía de conocimientos lingüísticos y recogió lo mejor que supo las particularidades propias del habla de lo que ya entonces era una sub-cultura.

El texto del MS1221 muestra numerosas discrepancias en el modo de escribir palabras, puestas a veces en boca de un mismo personaje. Así, enjunto y defunto, arenquis y jarenquis. No pueden tenerse muy en cuenta estas variantes fonéticas pues los diferentes mss. que conocemos son copias del texto original y muestran las variantes debidas a diversos amanuenses.

A juzgar por los textos, el habla de aquellos marineros tenía algunos rasgos fonéticos que hoy sólo aparecen en las zonas rurales del interior de Cantabria. Me refiero a dialectalismos como el cambio de la $e$ final no acentuada en $i$ : dici por dice, y de la $o$ final no acentuada en $u$ : hechu por hecho. Características que podrían explicarse por el hecho de que los mareantes se dedicaban también a la labranza de viñas en un Santander de reducidas dimensiones circundado por tierras de labor, como el resto de las demás villas de la costa.

Otros vulgarismos que se hallaban tanto en el interior como en la costa serían los casos de metátesis: probe por pobre; de disimilación: denguno por ninguno, mártiles por mártires; de asimilación: dicis por dices; de contracción: lido por leído, o de pérdida de la $d$ intervocálica en sílaba final: bocao por bocado.

García Diego quiso representar los hechos tal y como eran aunque añadió rasgos caricaturescos para dar carácter cómico a una situación originalmente lacrimosa. La acción tiene lugar en época contemporánea, los actores van vestidos como los mareantes en días de

13. Amós de Escalante reproducía un pasaje del prólogo de García Diego a su entremés, del que cito las siguientes líneas: "Se ha procurado, en cuanto es posible, pintar lo que pasa en las Buenas glorias, usando de las mismas frases, conversaciones y modo con que se explican en ellas los devotos y apasionados de estas perniciosas congregaciones. Esto privará al escrito de aquella gracia que pudiera ofrecer, si se le vistiese de otra gala y expresiones; pero aunque éstas pudiesen desde luego ser más adecuadas para excitar la risa, no conducirían tan oportunamente para el intento a que se dirigen. Aquí se procura hacer irrisible este uso, valiéndose de sus propias armas para combatirle. La sisa del vino, la venta y el empeño de los propios vestidos, las quimeras de los maridos y la escandalosa embriaguez de las mujeres, no son casos inventados en la imaginación y fantasía del autor para atraer el gusto de los espectadores. Tienen el mérito real de ser lances sucedidos efectivamente en esta ciudad, con motivo de las Buenas glorias. Y en ellos se dejan ver las fuerzas que cobra una vil pasión cuando el hombre se entrega a su duro dominio y le sacrifica sus más estrechas obligaciones. Esta es la idea.» 
ceremonia, hablan de asuntos que resultaban familiares a todos los presentes y se expresan con una naturalidad y una gracia comparables a las de los personajes de Cruz o de González del Castillo. El proceso de la engarra entre pescadoras, que comienza por una nadería, sufre varios altibajos matizados de reticencias y de pullas hasta desencadenar una tempestad de acusaciones y de insultos. Acaba en un combate en el que intervienen uñas, bocas, pelos, manos y pies. Riñas y gentes como las de esta Buena Gloria del siglo XVIII reprodujo Pereda en su propia versión del velorio o en Sotileza, casi un siglo más tarde. Quienes como yo hayan conocido todavía la vida marinera que bullía en la calle de Tetuán y en Puertochico recordarán las barquías, boniteras y parejas que traían el pescado a la Almotacenía para la subasta, y que llenaban la dársena, los carros de mano pintados de rojo o de azul cruzando por delante de La Austríaca, y las ferias del Carmen, plantadas todos los años al principio de Castelar, donde estaba la Comandancia de Marina. Recordarán también las engarras de las pescadoras, épicas e interminables, calcadas casi de aquellas del siglo XVIII y en las que se usaban, con renovada furia, expresiones e insultos centenarios. Seguro que tales insultos -bribona, puta, pellejo, alcagüetona, borracha, recochina- hicieron torcer el gesto a los moralistas pero García Diego, quien los usó aquí precisamente para moralizar, se excusaba al advertir en una nota sobre uno de ellos que aunque "esta palabra no es limpia se pone por ver si se destierra de entre los mareantes, que la dicen a cada paso».

Criticaba aquél las Buenas Glorias por juzgar que daban ocasión a quienes participaban en ellas de gastar en bebidas un dinero que a veces no tenían y a emborracharse. Como no eran dueños de sus actos escandalizaban, reñian, se pegaban y eran víctimas de la lujuria y del desenfreno. Además criticaban y quitaban la honra a sus semejantes, daban mal ejemplo a los niños que llevaban a tales ceremonias y acababan arruinando a sus familias. Al final del entremés, el honrado artesano Francisco aparece para defender a sopapos la institución matrimonial; le respalda moralmente un Alcalde de barrio quien recomienda, muy serio, como panacea para la esposa levantisca: «que sienta después lo que es el pino / rompiéndola los huesos a trancazos».

Parece que las Buenas Glórias no eran ya lo que fueron antes al decir de la Manuela ("perdiendo... se va ya la caridá") y de la Lucía ("Me alcuerdo... no faltaba antes un alma" vs. 186-191), sin embargo, el moralista reconocía que no había manera de acabar con la costumbre pues con la gente de mar no se podía. 
El texto contiene numerosas referencias a la vida local del momento, la mayoría de gran interés por referirse a sucesos y costumbres de Santander y en una época sobre la que hay escasísimos testimonios literarios.

Los mareantes viven en su propio mundo y sus conversaciones giran en torno a incidencias de la pesca, a rivalidades de oficio con los del Cabildo de Arriba (llamados también los de Puerta la Sierra) y a la marcha de la guerra con los ingleses por lo que ésta afecta su vida o la de sus familiares y amigos embarcados. Relatan anécdotas de temporales y naufragios, y los que han servido en Cádiz recuerdan con nostalgia el pan, el vino y el clima de aquella tierra y los comparan con los de la propia. Tanto llueve en Santander que al descontentadizo Simón le parece vivir «en el orinal del mundo» (vs. 473).

Las pescadoras usaban saya, falda y jubón y se cubrían con mantillas, y los mareantes capa cuando iban de ceremonia. Todos eran amantes del mosto y los hombres, al menos los del Cabildo de Abajo, solían tomar vasos de vino blanco en una taberna «junto al antiguo Correo" y, antes de ir a la mar, echaban la parva una o más veces donde la Tomasa. Para merendar tomaban queso, arenques, nueces y percebes, que serían de poco precio entonces, acompañados de gallofas, un pan muy estimado siempre en Santander.

En el «Entremés de la Buena Gloria» hay también ecos del cambio de vida que experimentaba la ciudad por entonces. Sabido es que durante la primera mitad del siglo XVIII Santander era una pequeña villa de escasos recursos y ocupada principalmente por marineros y labradores. Contaba con un barrio en alto agrupado en torno a la iglesia Colegial de los Cuerpos Santos y con otro en la parte baja, ambos comunicados por un puente. Desde el Alta había terrenos en declive hasta cerca del agua principalmente dedicados al cultivo del maíz y de las vides, de las que sacaban el "vino patrimonial" o chacolí, un vino ácido de pocos grados ${ }^{14}$. A estas faenas solían dedicarse las mujeres mientras los maridos estaban en la mar, o éstos mismos cuando no podían salir de pesca. La entrada a Santander era por Becedo, ca-

14. Emeterio pondera el chacolí local (verso 485) y Juan el prometedor estado de las viñas (vs. 674-5). Véase Fernando Barreda, "El chacolí santanderino en los siglos XIII al XIX", Altamira, 1-3 (1947), 5-76. 
mino real bordeado de chopos que a principios del XIX quedó ampliado para hacer allí la Alameda Segunda ${ }^{15}$.

La vida monótona y patriarcal de aquel lugarón cambió rápidamente con la apertura del camino hasta Burgos (1748-1753) para la exportación de lanas a Europa. En 1755 Santander alcanzó el rango de Ciudad y de Obispado; más tarde, después de promulgarse el Real Decreto de 1778, el puerto quedó habilitado para el comercio con Ultramar y tuvo más preeminencia el camino a Palencia, pues desde allí venían la harina y el trigo para América. Santander contaba ya con una burguesía poderosa de comerciantes y armadores ${ }^{16}$; desde 1765 había comenzado el saneamiento y ampliación de la dársena y en 1787 fue elegido Regidor el conde de Villafuerte, que tanto hizo por el adelanto de la ciudad ${ }^{17}$.

Tanta prosperidad atrajo en pocos años a muchos inmigrantes llegados desde los pueblos del interior y de la costa ${ }^{18}$, desde otras provincias y aún desde fuera de España. Según Martínez Vara ${ }^{19}$ en 1753 Santander contaba con 2.700 habitantes y en 1782 tenía ya 4.752. Un escrito dirigido por el Ayuntamiento a Carlos IV en 1800 señalaba que la población de Santander «no se compone, como otras, de vecinos arraigados, connaturalizados y constantemente establecidos, siendo en la mayor parte venidos allí de veinte o pocos más años a esta parte, atraídos por la ventajosa situación de su puerto...» ${ }^{20}$.

Para esta edición he seguido el texto del manuscrito MS1221 pues me ha parecido el más fidedigno. Señalo con un asterisco las variantes halladas en el manuscrito MS43, que es el otro completo que conozco. He recogido también aquellas que afectan al sentido del texto y que aparecen en los fragmentos del sainete reproducidos por $\mathrm{Pe}^{-}$

15. «Esa calzada / que de árboles se mira y ve cercada / por una parte del camino» (vs. 25-27).

16. «El comercio le veo muy medrado / y si la guerra cesa brevemente / podrá llegar a estado floreciente» (vs. 18-20).

17. Véase Tomás Martínez Vara, Santander de villa a ciudad. (Un siglo de esplendor y crisis), Santander, Colección Pronillo, 1983, caps. I y II (pp. 23-138).

18. Antón recuerda "cuando en Santander no había más que el barco de mi güelo" y Emeterio desdeña a los pescadores foráneos "que de ayer acá vinieron" (vs. 666-74).

19. Ibíd., p. 62.

20. Citado por Martínez Vara, pág. 59. 
reda (P) y por Amós de Escalante (JPL). También he puesto al día la ortografía y la puntuación.

\title{
ENTREMÉS DE LA BUENA GLORIA
}

Personas:

\author{
Francisco: Artesano de Santander \\ Justo: Vecino de Santander \\ Prudencio: Amigo suyo forastero \\ Simón: Marinero \\ Antón: Marinero \\ Emeterio: Marinero \\ Antonia: Vecina de Santander \\ Ana viuda: Vecina de Santander \\ Manuela: Parienta de Ana \\ Lucía: Parienta de Ana \\ Tomasa: Parienta de Ana \\ Dos niños \\ Dos alcaldes de Barrio
}

(Salen Prudencio y Justo)

Pru.: Amigo, Santander es reducido

pero es un pueblo alegre y muy pulido.

Just.: Conque, vamos ¿te gusta aqueste puerto?

Pru.: Yo creí que venía a algún desierto sin trato racional y sin cultivo / mas, a fe, que mi engaño era excesivo porque he visto las cosas tan en punto como en las demás partes.

Just.: $\quad$ Y pregunto ¿qué es lo particular que aquí te agrada?

Pru.: Todo, amigo. No he visto hasta aquí nada que no sea conforme a un pueblo grato: mucha atención, política en el trato, en las damas también mucha belleza, agrado, discreción y gentileza.

Just.: ¿Y de los caballeros?

Pru.:

Nada menos:

políticos, afables, en fin, llenos

de nobleza. Sí, amigo, voy prendado,

el comercio le veo muy medrado

y si la guerra cesa brevemente

podrá llegar a estado floreciente. 
Just.: Y entre cuanto aquí has visto y advertido dime cuál singular te ha parecido.

Pru.: He visto varias cosas que sin duda hay bastante primorosas. Me ha servido de gusto esa calzada que de árboles se mira y ve cercada por una y otra parte del camino. La Catedral es rara, yo imagino que a caso será sola por fortuna, viéndose tres iglesias en sólo una ${ }^{1}$. Los muelles son capaces y seguros, / los aires muy templados, sanos, puros, la ria, playa amena y anchurosa, la entrada defendida, vista hermosa; el castillo parece fue palacio y esto es lo que me falta ver despacio. Si no tienes que hacer, vente conmigo, serás mi introductor.

Just.: $\quad$ Vamos, amigo... pero espera, ¿es preciso verle ahora?

Pru.: ¿Preciso? No por cierto, a cualquier hora, mañana o cuando quieras.

Just.: $\quad$ Muy bien, deja, que la fortuna aquí nos apareja la mejor ocasión de divertirnos. que se pueda ofrecer para reirnos.

Pru.: ¿De qué suerte?

Just.: $\quad$ Verás lo que es en breve y quedará cumplida según debe vuestra curiosidad de tal resulta. Has de saber que en esta ciudad culta, cuyo racional trato es distinguido, hay desde tiempo antiguo introducido cierto hábito * con nombre de antigualla que llaman Buena Gloria, y que se halla * solamente entre algunos artesanos, que más que de ciudad aun son aldeanos. Cuando alguna persona entre éstos muere (sea anciano, sea niño, o el que fuere) $/$ se juntan en la casa del difunto habiéndole enterrado (pues es punto) y ha de ser por la tarde, no te asombres. Acude una caterva en tropa de hombres y un ejército fiero de mujeres, abandonando todos sus quehaceres;

1. Desde el siglo VIII las cabezas de San Emeterio y San Celedonio estuvieron enterradas en la iglesia del Cristo en lo que parece haber sido el hipocausto de unas termas. El lugar fue excavado en 1972 por los arqueólogos Joaquín Echegaray y J.L. Casado, quienes hallaron restos de edificaciones romanas. 
no queda pariente ni allegado, conocido, compadre, ni un ahijado, madrastras, nueras, tías y sobrinas,

cuñadas, compañeras y vecinas,

lo mismo que un enjambre de ratones aparecen allí por los rincones.

Tú acaso no sabrás a qué se juntan y tal vez pensarás * que allí tributan

algún diario * sufragio para el muerto.

Pues sábete que en todo este concierto no hay otro fin, impulso ni motivo que el deseo bendito y compasivo de llenarse de vino; asi se hace, cada cual a su antojo se resarce y como hay para todos puerta franca nadie sale de allí sin una tranca.

Pru.: ¿Las mujeres también?

Just.: ¡Oh! ¡Qué dislate! Ésas tan sólo mojan el gaznate pero a tres azumbritas, en limpieza suele salir de allí cada cabeza.

Pru.: ¡Jesús! ¡Válgame Dios! ¿Cómo es posible/ que una costumbre vil tan reprensible que de barbarie casi poco dista, bajo de ningún título subsista?

Just.: Entre gente común sólo sucede porque con las razones no se puede sacar partido bueno, y se tolera.

Pru.: ¿Cómo? ¿Qué? ¿Una insolente borrachera tan pública, $\tan$ vil, escandalosa, y en mujeres ¡Oh Dios! tan perniciosa, se puede permitir?

Just.: $\quad$ ¿Sabes de dónde proviene esa costumbre?

Pru.: $\quad$ Se me esconde.

Just.: Sabe, amigo, que viene nada menos que del rito gentil: mira qué buenos créditos la antigualla esa reserva, pues costumbre pagana aún conserva.

Pru.: Esto es cierto y constante porque de un modo igual muy semejante hacían los paganos también juntos las fúnebres exequias de difuntos. Llamaban a estas fiestas Saturnales, donde con los excesos más cabales llegaban a perder razón y juicio, dejando al vino hacer todo su oficio. A esta disolución y extrema furia seguía por sus pasos la lujuria con total abandono y desenfreno. 
Just.: Eso acá no tenemos.

Pru.: $\quad$ ¡Oh, qué bueno!

¿Después que estén de vino bien repletos /

te parece estarán para respetos?

$\mathrm{Y}$ esas mujeronazas, cubas viejas, después que hechas estén unas pellejas...

Just.: Cabal. Ni más ni menos así pasa, hay veces que no pueden ir a casa.

Pru.: ¿Pues que extraño será que éstas se entreguen a cuantos no conozcan, mas que lleguen de Londres, de Ginebra o de Turquía?

Buena está, ya se ve, su sacristía para andar en reparos. Es vergüenza decirlo, cuanto más, y que no venza una sana razón que el juicio alumbre semejante desorden o costumbre.

Just.: Todo cuanto propones es debido, mas se halla de tal forma introducido que por más que se ha hecho y declarado * nada se ha conseguido ni logrado.

Pru.: Pues qué, ¿no se ha encontrado modo o medio de poder aplicar algún remedio?

Just.: ¿Remediar? Eso sí. Lindo despejo. Más que les desollasen el pellejo no podrían quitarles las costumbres de echar por cada muerto seis azumbres ${ }^{2}$.

Pru.: ¿No quitar? Sí, a fe mía.

Just.: $\quad$ Es excusado

Pru.: ¿Pues hay más que al primero que sea hallado en una buena gloria, de caliente, darle un par de semanas de presente / a pan y agua en el cepo?

Just.: ¡Brava prueba! ¿Y que remediarías?

Que no se beba

en esas Juntas feas, detestables. ¿Y no hay otros arbitrios?

Pru.: $\quad$ Sí, son dables.

Just.: Pues ved el mismo mal; si dan en eso cuanto juntar no puedan el congreso buscarán para hacerlo cobertera * y todos se pondrán como tambores.

2. «Azumbre»: Medida de capacidad para líquidos, compuesta de cuatro cuartillos y equivalente a dos litros y diez y seis mililitros. 
Pru.: Si cuando alguno de éstos se juntase * y en forma, de una vez, se escarmentase dándole juntamente un buen castigo viéranle * remediado.

Just.: iAh! Amigo, amigo, 150 lástima si te oyesen, te tendrían en la Puerta la Sierra.

Pru.: $\quad$ No lo harían.

Just.: Se ve bien que no sabes lo que es esto, y me alegra conozcas lo que es presto. En esta misma casa, hacia ese lado un hombre esta mañana se ha enterrado que mujer y seis hijos mantenía, y ha sido tal el ruido y gritería que a cuenta de los lloros del difunto no pude sosegar anoche un punto Ahora están a vísperas ${ }^{3}$, mas creo / no tarden en venir (a lo que veo) a hacer su buena gloria por el muerto, y desde el otro cuarto, a lo cubierto, verás lo que se estila en tales casos.

Pru.: No dejarán de ser bien lindos pasos, déjalo, que el oirlo me aborrece.

Just.: Ya llegan los del duelo, me parece, porque ruido se siente.

Pru.: Veámoslo ya que quieres.

Just.: $\quad$ Ya la gente

sube por la escalera. Ven, entremos, que a gusto desde allí lo observaremos.

(Retíranse los dos al otro extremo del paño y van saliendo los hombres con capas y velas en las manos, según van a los entierros. Luego las mujeres cubiertas con sus mantillas; formarán dos corrillos * separados los hombres de las mujeres. En el de éstas se pondrá la viuda toda cubierta a un rincón. Se procurará imitar en cuanto se pueda el tono de habla, acciones y gestos que se ven comunmente en esta clase de mujeres, pues en esto consiste toda la gracia del entremés.

Simón: Ya, tiu, no hay sino tener pacencia 4 .

Juan: Dios le presti al dejunto * su prasencia./

Antón: Compadre, Dios lo ha hechu, es escusau.

3. Los Oficios de Vísperas.

4. «El uso de este y otros semejantes terminachos pide no omitirse porque así lo pronuncian generalmente en estas concurrencias" (Nota del autor). "Efectivamente se hace así como supone el entremés y ésta es una antigualla de las Buenas glorias" (Nota del autor, JPL). 
Emet.: En paz esté su espíritu sosegau.

(Sigue ahora el coro de las mujeres)

Man.: ¿Han venío todas ya?

Lucía: Cuéntalas, mojuer

Toma.: Veremos:

Una, dos, tres, cuatro, cinco...*

Man.: Mojuer, Tomasa, ¿qué es esto?

¿No hay más a esta buena gloria?

Toma:: Mojuer, todavía hay tiempo.

Man.: No saben de obligacionis: para un empeño como éstos, aunque empeñara la falda. Hija, escusao es, perdiendo se va ya la caridá.

Lucía: Hija, dicís bien, me alcuerdo * que en habiendo buena gloria aunque fuese un probe el muerto no faltaba antes un alma.

Toma.: ¿Y ahora a cuánto escutaremos?

Lucía: A dos y medio * de plata.

Man.: ¡Eh! ¡Golosa! Para espenzar no tenemos.

A seis riales... ¿QQué lo quieres? ¿Que te lo lleven los * nietos? Anda con Judas, que te lleve. a tí y tou tu dinero. ¿No tienes quien te lo gane? ¿Si fuera yo! „Probe!

Lucía: Cierto / que puedes quejarte. Vaya, a seis riales * escotemos.

Man.: Bien, hijas, ahi va mi escoti.

(Tienden una mantilla en el suelo y alli echa cada una su pitanza) ${ }^{5}$.

Lucía: Ahí está el míu.

Toma.: Yatengo echau. Echa tú, Tona *.

Man.: ¿Está bien?

Toma.: Ya está cumpleto.

Lucía: Tomasa, ve por el vino ¿Sabes tú dónde lo hay güeno?

5. "Precio o estipendio que se da por una cosa". Diccionario de la Real Academia. 
Toma.: Mi comadre la María

(según ayer me dijeron)

vendi un vino tan hermoso

que puedi arder en un jueu ${ }^{* 6}$.

Man.: Pues, hija, antis que sacabi

veti, por Jesús, corriendu.

Toma.: ¿Cuánto trairé?

Man.: ¿ ¿Cuántos * semos?

Lucía: Siete no más.

Toma.: ¿ ¿Será güeno?

Que traiga catorce azumbres.

A dos por cabeza.

Man.: ¡Enfierno!

¿Siempre has de ser estrujera? *

No sabes codiar tu cuerpo.

$Y$ algunos niños, si vienen, ¿no han de probar algo de ello?

Que traiga veinti y dos * justas, /

en ocho más no paremos,

hijas, más vale que sobri

que no que falti.

Lucía: . Anda luegu;

y también trai diez gallofas ${ }^{7}$.

Toma.: ¿Y hemos de comer pan seco?

Man.: Pues trai también diez arenques

230

y libra y media de queso.

Mira si hay algunas nuecis porque percebias ${ }^{8}$ no es tiempo.

$\mathrm{Ve}$, que estamos aquí secas.

(Vase Tomasa)

Man.: iA quien enviasti por ellu?

Lucía: La Tomasa.

Man.: ¡Buena * alhaja!

Lus diablos te lleven luegu,

a buena parte a dar fuisti.

Ya sacará bien primero

antes que güelva el escoti ${ }^{9}$.

6. "Juego aquí es lo mismo que fuego; y así se explican cuando quieren decir que el vino es de mucha fortaleza" (Nota del autor, JPL).

7. «Gallofas»: Panecillo alargado esponjoso. Dicc. Acad.

8. «Percebias»: Percebes.

9. «Escoti»: Escote, lo que corresponde escotar o contribuir a cada uno. 
Lucía: ¡Eh! Mojuer, no digas eso.

Man.: ¿Aquélla? No la conoces, bien remojará el coleto a cuenta nuestra esta tarde.

Just:: (Al paño)

¿Ves cómo se honran los muertos en las buenas glorias? Pues asi se hacen sus entierros. Atiende a esas bribonazas que están esperándo ahí dentro como almas del Purgatorio que las llegue el refrigerio. / Pasemos aquí, a los hombres, verás qué concilio entre ellos.

(Sigue el coro de los hombres)

Emet.: Juan, a seis riales es poco; semos cuatro y cuando menos beberemos doce azumbris.

Antón: Simón, dice bien Miterio.

Simón: ¿Y no ha de haber también algo para atizar el rodezno? ${ }^{10}$

Emet.: Algo de acompaño, sí.

Juan: Pues ¿qué trairá?

Emet.:

Traiga queso.

Antón: Mejores son cuatro arenquis pues sin otro surtimiento somos los cuatro abonados para soplar un pillejo ${ }^{11}$.

Juan: Pues bien, vengan los jarenquis.

Emet.: Démosle antes el escote; a ocho riales será güenu.

Antón: Pues bien, échalo en el suelu, que ésta es una cirimonia que nuestros tataraguelos mus * dejaron prevenio se oservase con respeto en toas las guenas glorias.

(Tienden una capa y echan sus escotes en ella).

Emet.: Toma, Juan, ese dinero y hasta donde te alcanzare trae.

\footnotetext{
10. Para comer.

11. Para bebernos un pellejo de vino.
} 
Antón: Pero güelve lueu /

porque queda sin vitualla

este probe regimiento.

(Vase Juan. Sale Tomasa y con ella dos niños que traerán un botijo o calderón, pan, queso y lo demás que dicen los versos).

Man.: ¡Válgate Satanás! Tanto

como has tardado en traerlo.

Ya estamos secas de puro

esperarti: no lo siento

por mí, por la probe viuda

que está sin tomar sustento.

Toma.: ¡Hija! ¡Si vieras qué prisa!

Más había de duscientus

que esperaban *, y por mucho

favor, a mí me lo dieron.

Man.: Trae, echa acá ese botiju (Le destapa)

290

¡Jesús! Este no está lleno.

Toma.: Algo se balducaría ${ }^{12}$, como vini tan corriendu.

Man.: Mejor te lu habrás echao en el camino al coletu.

Toma.: ¡Eh! ¡la grande desollada! ${ }^{13}$

No viene mi casta de esu;

borracha serás tú.

Antonia:

Calla.

No riñáis ni alborotemos,

tened lástima a la viuda

que ha enterrao su consuelo.

Viuda: ¡Ay!

Lucía: Hija, encomendarle a Dios. *

Toma: Si, hijas, vaya. /

Man.: Arrecemos

por los que han muerto en la calle.

(Murmullan entre sí en tono de rezar)

Por todos los que han muerto

en el servicio del Rey ${ }^{14}$,

Pater noster ${ }^{15}$...

12. «Balducar»: Derramar, verter.

13. «Desollado-a»: Descarado, sinvergüenza. Dicc. Acad.

14. Se refieren a los difuntos vecinos de la calle y a los que murieron sirviendo en la Armada.

15. «Observan estos rezos en las Buenas glorias para dar principio a sus sesiones. ¡Qué buenos rezos!» (Nota del autor, JPL). 


\section{Arrecemos}

por el que se hace el ufragio ${ }^{16}$

para que Dios le haya hecho

la güena * partida a su alma.

310

Pater noster...

Viuda: ¡Ay, probe! * ¿Qué sin consuelo

he quedao, sola y triste

sin mi amado compañero!

\section{(Aráñase)}

Toma.: Hija, vaya, no sea tonta, no llores; aquél ya es muerto, no te mueras tú. Manuela, echa de beber.

Man.: $\quad$ Echemos

antes un bocao.

Lucía: $\quad$ Vaya.

Toma.: Dale a la viuda primero;

trae acá vino. Toma *, hija, come ahora.

Viuda: $\quad$ ¡Ay! Que no puedo atravesar un bocao.

¡Ay, Santos Mártiles viejos! ${ }^{17}$

¿Qué desamparada y sola

me habéis dejao! ¡Qué negro *

fue este día para mí!

¡Ay, desdicháa!

Man.: Ya de eso, /

hija, ni * te has de alcordar, mañana iremos lo mesmo.

Toma de beber, que no has metío nada en el cuerpo.

Viuda: ¿Que no lo puedo pasar! ¡Ay, mi Juan! Mi compañero, ¿cómo podré yo olvidarte?

$$
\text { (Bebe) }
$$

Lucía: Echa de beber ¿Qué hacemos?

Man.: Hija, no eches en la jarra

de medio cuartillu, quiero

que me eches en la de azumbre.

Antonia: A mí también.

Lucia: $\quad$ Yolomesmo.

16. "Ufragio": Sufragio.

17. «Mártiles viejos. Alude a las efigies viejas de los Santos Patronos, que había antes que se quitase el antiguo retablo" (Nota del autor, JPL). 
Toma.: ¡Eh! ¡Mira las borrachonas!

Que vus traigan un pillejo,

el diablo os lleve. Tomad

hasta que reventéis, cueros.

(Dales la jarra y beben)

Just.: (al paño)

¿Has visto tal insolencia

ni tan público desuello?

Pru.: Varias provincias he andado,

he estado en diversos reinos,

en Londres, Ginebra, Holanda,

y te afirmo desde luego

350

que no he visto en parte alguna

semejante desarreglo

ni disolución igual

en mujeres por extremo

como éste.

Just.: Pues no es nada /

para lo que verás luego.

Atendamos a los hombres

que están en otro hemisferio.

(Sigue ahora el cuartel de los hombres, que para este tiempo han sacado su correspondiente vitualla como las mujeres)

Simón: A que Dios nos junte a tous

con el enjunto en el cielo. (Bebe)

360

Emet.: O todos pues o denguno, compadre.

Antón: Amén.

Juan: $\quad$ Eso es cierto.

Simón: Un * buen hombre era el defunto

¿Qué pacífico! Yo puedo

decir que en decisiete años

365

que navegué con él, dentro

de la Capitana en Cáiz

no tuvimos un encuentro.

Juan: Muy * amigo de sus amigos;

no hubo día en este invierno

370

que no hiciésemos vesita

a la Tomasa ${ }^{18}$. (Bebe)

Emet.: ¿Qué atentu!

No iría a la mar jamás

aunque emportase un emperio

sin echarse de aguardiente

cuatro parvas ${ }^{19}$ por lo menos. (Bebe)

18. "Una aguardientera muy conocida" (Nota del autor, JPL).

19. "Echar la parva": Desayuno ligero, por lo general, un sorbo de aguardiente. 
Antón: Ay, mi compadre benditu, alcuérdate desde el cielo cuantas veces juimos juntus allá, a un lao del Correo ${ }^{20}$. (Bebe)

(Siguen las mujeres)

Man.: Echa por acá esa jarra, Locía.

Toma.: $\quad$ ¿Eh, fatas! ${ }^{21}$ Que luego quereis volver a beber, desolladotas sin suelo, que no venís sino a hartaros; tenéis buen embucadero.

Man.: ¡Mira tú la borrachona! Ya van seis veces arreo ${ }^{22}$ que has bebido y yo una sola. ¡Venga esa jarra!

Toma.: No quiero

que ha dado por ahí * la güelta

sieti veces por lu menos.

Man.: También * como tú lo pago.

Antonia: ¡Eh! No tenéis miramiento.

Tenéis a la probe viuda

sin beber con vuestros cuentos.

Dale de beber.

Toma.: Toma, hija,

Dios te de salud y esfuerzo

para incomendarle a Dios.

Yo quedé viuda lo mesmu /

que tú, de venti dos años, que se me ajuegó y por eso no me ha faltao hasta aquí $\mathrm{Su}$ Majestá. (Bebe)

Man.: $\quad$ Yo lo mesmo.

Quedé con cinco familias

sin más amparo que el cielo

y los he criao a todos. (Bebe)

Viuda: Ay, hijas, que yo no pueu

olvidar a mi Juan, que era

el probecito tan güeno *

que aunque yo viniese a casa a deshora en cualquier tiempo jamás me dijo palabra.

Era un bendito, un cordero.

\footnotetext{
20. "Taberna de vino blanco, junto al antiguo Correo" (Nota del autor, JPL).

21. "Fatas": Tontas.

22. "Arreo": Sin interrupción.
} 
¡Ay, dondi encontraré otro!

¡Oh, Virgen de los Remedios!

¡Qué sombra me fue de casa! (Bebe)

Antonia: Majuer, ten intendimientu;

espántome de tus cosas.

Dios no falta en dengún tiempo. (Bebe)

(Siguen los hombres)

Juan: Simón, dicin que ya hay paces. (Bebe)

Simón: Así se corre por cierto. (Bebe) *

Antón: Yo lo que oí ayer mañana /

a mi primo, fue que el herno *

tuvo carta de su hijo

en que le dici eso y esto.

Emet.: ¿Qué le dicia?

Antón: Queganamos

aquellu, que no perdemus.

Emet.: Eso ya me lo dijeron.*

Antón: Yo he oído que habemus hecho

muchas cosas por allá

en América, muy lejos,

donde se llama... haya diantres,

entre los dientes lo tengu...

Simón: ¿Será Güenos Aires?

Antón:

Sí,

allá hacia Montevideu, donde vusté estuvo, compadre, cuando aquel barco de cueros.

Juan: Allí parece que ha hubío muchas murcillas y que esos perros de ingleses llevaron para peras.

Emet.: $\quad$ Yo mi * alegro, que esos bribionis no vienin por acá más que a traernus pesadumbris y trabajus.

Antón: En poniéndose del puerto a la vista naide puedi ganar un cuarto, pues lueu como piratas acudin y hasta el barco y aparejo * roban./

Simón: ¡Pícaros, canallas! (Muy enfadado)

No estaría satisfecho

hasta que los viese a tous

tendidos y patitiesos. 
Emet.: ¿Dónde?

Simón: Murdiendo la arena $\quad 455$ del Puntal o el Sardinero.

Antón: ¡Viva Simón! que merece otro trao más por eso.

(Bebe y siguen las mujeres)

Man.: Bebe, hiju mío. Pepucu *, (Habrá dos niños que no hablan) ${ }^{23}$ toma pan, arenqui y queso.

Toma.: ¡Eh, diablus! ¿Tenéis más hijos que trayer para acá drento? Trayed también al marío," Satanás us llevi.

Man.: ¿Quieru!

Deja las probis criaturas...

tragonazas, que estáis creyendo que vus ha de faltar: tumad aunque * reventéis con ello.

(Siguen los hombres)

Simón: Hombre, ¿hay sol en esta tierra o se le ha tragao el cielo?

Juan: ¿Por qué lo dice, compadre?

Simón: ¿Por qué ha de ser? Si esto creo que es el orinal del mundo.

¡Aun no he visto un día bueno desde què vine a esta tierra!

Aquí debe mear el cielo. /

Antón: ¡Cuánto mejor era Cadi! *

Simón: Como Cadi * ni aun el cielo. Mire vusté qué pan éste ${ }^{24}$ : éste en Cáiz ni los cerdos, con perdón, lo mirarían.

Aquí un hombre, no hay remedio, se ha de morir o comer lo mismo que los de Cueto.

Emet.: El chicolí no está malo.

23. «Ha de haber dos niños que representen los que las madres suelen llevar en su compañía a las Buenas glorias" (Nota del autor, JPL).

24. «Es abuso de los mareantes cuanto vienen de otros parajes despreciar todo lo de su país" (Nota del autor, JPL). 
Simón: Para aquí, bastante, pero ¿dónde está aquél que mus daban en la Carraca? ${ }^{25}$ Todo esto es lo propio que una escoria; pasa aquí un hombre por ello 490 porque es fruto de la tierra.

Antón: Simón, si dura este tiempu no ha de matar uno un pez.

Simón: No tienes conocimiento: el año de mucha boga, mucha pesca, estate en eso.

Juan: Compadre, a cesta y jareta vengan hombres.

Simón: Yo me atrevo
si voy a la mar de muerta una sardina y un muergo besugo perro al instante 27 ; cada cuerda nuevecientos. / ¿No es verdad?

Juan: $\quad$ Sí, y echa un trao que lo mereces por eso. (Bebe) Vales más que todos juntos los de ara la puerta ${ }^{28}$.

Emet.: Ello

lo dirá. Vusté, compadre, habla mucho y hace menos.

Juan: Yo sé más que no vusté. Sí. Yo lo dío, y que tengo más obligación también.

Emet.: ¿Qué ha de tener? Que ni el remo sabe coger en la mano ni meterle en el estrepo ${ }^{29}$.

Juan: Pues vusté ni naide acaso, con todo que osté es más viejo, me han de enseñar el oficio.

25. "La Carraca»: El Arsenal de la Isla de San Fernando en Cádiz.

26. "Sitio determinado de pesca" (Nota del autor, JPL).

27. "Besugo perro: Expresión que les es muy común" (Nota del autor, JPL).

28. "Así llaman a los de la Calle Alta, entre quienes hay cierta emulación" (Nota del autor, $J P L)$. El barrio de pescadores se llamaba desde la Edad Media de «Fuera la Puerta".

29. "Término de mar: Rollo donde se afirmà el remo" (Nota del autor, JPL). 
¿No me había yo primero

de ensuciar en toa el alma? ${ }^{30}$

Antón: Simón, hombre, aquí no es tiempo

de que habléis en esas cosas,

comendad a Dios al muerto

y dejarvos de desputas.

Simón: Eso, bien. Un trao luego, que en lo que es obligación

denguno hasta aquí me ha puesto

delante el pie.

Juan: $\quad$ A mí tampoco.

Emet.: ¿Otra vez volvéis a eso?

¿No miráis en dónde estáis?

¿Ni que ha salido hoy un cuerpo

de esta casa?

Simón: Dicis bien.

Venga un trao en señal de eso. (Bebe)

(Siguen las mujeres)

Lucía: ¿No han venio las mis hijas?

¡Ay, probetucas! * Partiendo

me están aquí el corazón;

este pocucu de quesu

he de guardar, las mis probis,

que se estarán deshiciendo.

Toma.: ¿Cuántas tienis?

Lucía: $\quad$ Mojuer, tres, pero las dos no hay remedio

de que proben un bocao, alguna alma mala * temo que me las va hiciendo mal.

Antonia: Hija, a la mi Paca * tengo yo de la misma manera.

Lucía: Yo tantísimos remedios les he hecho, mojuer, que más de diez pesos duros llevo gastados, y no sé qué es, que se me van consumiendo y yo tengo mal escajo.

Toma.: ¿La han lidu los Evangelios? ${ }^{31}$

Lucía: No, mojuer.

30. "Aunque esta palabra no es limpia se pone por si se destierra de entre los mareantes, que la dicen a cada paso" (Nota del autor, JPL).

31. Como exorcismo para sacarle los demonios del cuerpo. 


\begin{tabular}{|c|c|c|}
\hline Toma.: & $\begin{array}{l}\text { Pues no seas tonta, } \\
\text { no la hagas otro remedio / } \\
\text { que ése es mal de fuera claro }{ }^{32} \text {. (Bebe) } \\
\text { (Siguen los hombres) }\end{array}$ & 555 \\
\hline Juan: & $\begin{array}{l}\text { Ya le he dicho a vusté ya } \\
\text { que denguno de la Puerta } \\
\text { me ha de venir a enseñar } \\
\text { lo que es el oficio a mí. } \\
\text { ¿Cuándo será vusté capaz } \\
\text { de verse como me he visto? } \\
\text { Venir un golpe de mar } \\
\text { contra el barco por la proa } \\
\text { y sin poder gobernar } \\
\text { virarse toda la quilla } \\
\text { y yo firme por detrás. } \\
\text { Si vustedes no son hombres } \\
\text { más que en casa. }\end{array}$ & 560 \\
\hline Simón: & $\begin{array}{l}\text { ¿Eso no más? } \\
\text { Cuando he salío yo a congrio } \\
\text { nueve o diez veces allá } \\
\text { he estado si quedo, Antón ¿eh?... } \\
\text { Cuando Pepe, el de Colás, } \\
\text { se ajuegó * ¿ ¿Se alcuerda vusté? }\end{array}$ & 570 \\
\hline Antón: & $\begin{array}{l}\text { Y me he de alcordar * jamás } \\
\text { que aquel día fui a echar juera } \\
\text { una freata }{ }^{33} \text {, y al dar } \\
\text { güelta para el puerto a poco } \\
\text { semos ánimas. }\end{array}$ & 575 \\
\hline Simón: & $\begin{array}{l}\text { ¿Qué tal? } \\
\text { Diga vusté. }\end{array}$ & \\
\hline Antón: & $\begin{array}{l}\text { Nunca he visto / } \\
\text { mayor marejáa, el mar } \\
\text { mus quería comer vivus. }\end{array}$ & 580 \\
\hline Simón: & $\begin{array}{l}\text { Pues yo andaba por allá, } \\
\text { que mus cogió sobre Suancis } \\
\text { al venir, un temporal } \\
\text { de forma. Mire vusté, } \\
\text { al primer golpe de mar, } \\
\text { palo trinquete y escota, } \\
\text { todo fue con Satanás. } \\
\text { ¡Aquello si que era! }\end{array}$ & 585 \\
\hline Juan: & $\begin{array}{l}\text { Antón, } \\
\text { beba vusté. }\end{array}$ & \\
\hline
\end{tabular}

32. «Cree esta gente que hay brujas y hechizos y a la más pequeña indisposición de los niños la atribuyen a aquellon (Nota del autor, JPL).

33. Remolcar con una embarcación a remo una fragata hasta sacarla de la bahía. 
Antón: A navegar

donde estén * los de aquí, vamos, no son gente los demás. (Bebe)

(Siguen las mujeres)

Toma.: Mojuer, dame aquellos riales que me debes, que ya es tiempo, y estoy yo en necesidá sin mi Francisco saberlo.

Man.: ¿Eh? ¡Diablo! ¿No tienes más que echarme en cara más presto? ¿No tenías otra parte donde pedirlo?

Toma.: $\quad$ No tengo de estar sin ellos por ti.

Man.: Pues yo ahora no los tengo.

Toma.: Buscarlos. ${ }^{*}$ El Judas de ella que se anda de mí escondiendo. Si es para ir al vino blanco no te falta a tí dinero.

Man.: Borracha lo serás tú $\mathrm{y}$ tu casta, pues no vengo / yo de eso. ¿Oyes, Locía?

Ven, ven, huéleme * el aliento.

El diablo la borrachona que es capaz de echarse entero un cuartillo de aguardiente sin alentar ${ }^{34}$ en el cuerpo y tiene que decir.

Toma.: Oyes,

has de saber que no vengo yo de casta que me topen borracha nunca en el suelo, ni que me traigan a casa. Cabalito, sí. Y no es cuento.

Man.: Oyes, mira bien lo que hablas, que no eres en dengún tiempo tú para puesta conmío. Has de saber que yo tengo parientes, y muy honrados, que han metido barba drento de cáliz ${ }^{35}$, lo que tú no;
34. «Alendar»: Respirar.
35. «Meter barba en cáliz»: Ser sacerdote. 
y este jugón ${ }^{36}$, aunque viejo,

has de saberte que tiene

mucha honra, que aquí no hay mico ${ }^{*}$.

630

Toma.: ¡Eh! ¡Mira la fanfarrona!

Has de saber que tan güenos

o mejores que los tuyos

tengo yo parientes, pero

no los doy * tanto a entender.

635

Man.: ¿Como los míus? ¿Un cuerrr...no... para tí!

Toma.: Sí, muchu, muchu. /

Man.: En tu vida, ni tú ni ellos.

Anda, vete noramala

¡Deslenguada! Que te dejo

como lo que eris no más.

640

Toma.: Has de saberti que echo

bien el pie y que cuando salgo

a la calle voy derecho, que en sacudiéndome así (Sacude la saya)

todo tras de mí lu dejo.

Man.: También yo, que has de saber

que en la cara y frente llevo

mucha honra; eso sí, cabal,

cabal, cabal que la tengo;

650

que a denguno de los míos

le han topao en dengún tiempo

debajo la cama hurtando

las calderas ${ }^{38}$, como han hecho

a los tuyos.

Toma: $\quad$ Eso mientes,

desollada.

Man.: $\quad$ No, no miento.

Toma: Mira tú la cantonera ${ }^{39}$.

Lucía: No vendréis * aquí a poneros así; mirad a esta probe.

Antonia: Vaya, vaya, dejad eso.

Echad un trao. Tomasa, venga la jarra.

36. "Jubón": Vestidura que cubre desde los hombros hasta la cintura ceñida y ajustada al cuerpo. Dicc. Acad.

37. «No hay mico»: No hay engaño.

38. «Expresión y ademán comunísimo cuando riñen» (Nota del autor, JPI).

39. "Cantonera": Prostituta, mujer pública que anda de esquina en esquina atrayendo a los hombres. Dicc. Acad. 
Man.: A mí lueo. (Beben)

(Siguen los hombres)

Simón.: En lo que toca al trinquete, virar de bordo, izar remos, la mesana, subir gavias / y el codo ${ }^{40}$, vengan hombres. (Bebe)

Emet.: Todos esos seis petates que de ayer acá vinieron son unos trastos que yo los conocí a todos ellos sin camisa. (Bebe)

Juan: QQué gran muestra tienin las viñas, Miterio! (Bebe)

(Las mujeres)

Man.: El mundo está ya perdío.

Lucía: Hija, dicis bien, es cierto que las" solteras de agora andan en * tanto desuello que es una mala vergüenza. (Bebe)

Viuda: No era asi en nuestro tiempo.

Man.: ¿Visti hoy la hija de la Juana?

Toma.: ¿Cuál?

Man.: La mayor.

Toma.: Sí, por cierto. Hija, me dejó espantada. ¡Qué saya! ¡Qué jubón nuevo! ¡Yo no sé de dónde sale! Porque un probe marinero no puede dar para tanto. (Bebe)

Viuda: ¡Ay, bobas! No va muy lejos a buscar quien se lo dé.

Man.: Mojuer, ¿Quién es? /

Viuda: Un galleo que anda ahí capitán de un barco, el cual ni vivo ni muerto sale de su casa *. Aquí antes de ayer me dijeron si estaba o no dél preñada:

40. "Y el codo": Beber. 
lo que me han dicho vus cuento. (Bebe)

Just.: (Al paño) Mira cómo andan las honras entre estos demonios fieros.

Pues en todas pasa así

¿Ved qué buenas glorias!

Pru.: ¡Cielos!

¿Qué infame cátedra es ésta

de maldad y de veneno?

Man.: Mojuer, echa de beber.

Toma.: No hay más...

Man.: ¿Cómo ha síu estu?

¿Mojuer, dónde ha ido ese vino?

Toma.: ¿Había de ser eterno?

Lucía: Oyes, debajo la saya (Aparte) he visto estar escondiendo una jarra a la Tomasa.

Man.: ¡Hola, Tomasa! ¿Qué es eso? ¿Dónde echaste la otra jarra?

Toma.: ¿Pues acaso yo la tengo ni la he visto, deslenguada?

Man.: Sí, tú la tienes ahí dentro

Toma.: ¡Anda, pícara borracha!

Man.: La borracha tú y tu güelo lo seréis, y se ha de ver quien la ha hurtado.

$$
\text { (Agárranse las dos del pelo) }
$$

Toma.: iSuelta el pelo!

Man.: No te ha de valer, bribona, alcagüetona. El gargüero te he de arrancar, dalo aquí. Mirar si tiene algo dentro de la saya. (Levántase y la registran)

Lucía: Sí, aquí está.

Man.: Te aseguro y te prometo, pillejona sin vergüenza...

Lucía: Dejarla *, vaya...

Man.: La tengo de beber la sangre aquí.

Simón: Hombre, que se matan creo las mojueres. 
Emet.: $\quad$ No ¡Maldita!

No tengas por eso mieo,

se darán cuatro cachetes

y se arañarán el pelo

pero nada más.

Toma.: ¡Vecinas!*

que me ajuegan, venid presto,

735

estas pícaras borrachas.

Juan: ¿Qué tenéis? ¿Por qué es aquesto?

(Continuan riñendo en tono alto)

Man.: Esta borracha ladrona.

Simón: Ea, apartad.

Man.: Deja el pelu.

Simón: Qué, ¿venís a alborotar?

Idus noramala, enfiernos,

ya es hora de ir a su casa

cada cual.

Toma.: Mira, no tengas *

de ser hija de Antón López,

cuando antes de muy presto

los hígados no te saque.

Ladrona, puta, pellejo,

alcahuetona, borracha.

Man.: Recochina, te protesto

que no has de...

Simón: ¿Queréis dejalo

o que vos muela los huesos?

750

¿El diablo de las mojueres!

¿Qué calientes están! Luego

vamos a casa. Haya Judas

de ganao tan perverso

755

que donde están jamás puede

haber quietud y silencio.

(Métenlas y se entran todos. Por la otra parte salen Justo y Prudencio.)

Pru.: Amigo, a no haberlo visto te aseguro y te protesto, no pudiera persuadirme que bajo ningún pretexto la disolución llegase a este escandaloso extremo. ¿Esto llaman buenas glorias?

Digan juntas del Infierno

porque esto es una gavilla de borrachos.

Just.: $\quad$ Punto menos. 
Pru.: ¡Y no haya una alma piadosa que movida de buen celo de cuenta a los superiores para que pongan remedio! (Dentro, Francisco)

Franc.: Te juro a brios, borracha ya curtida / que no te he de dejar costilla a vida.

Toma.: (Dentro) ¡Vecinos, acudir, que aquí me matan!

Just.: ¿Oyes qué gritos?

Pru.: $\quad$ Sí, a alguno maltratan.

Just:: Acudamos allá a poner remedio.

(Entranse y sale Francisco dando de palos a la Tomasa)

Franc.: Te he descuartizar de medio a medio, la falda has empeñado, gran demonio. ¿Dónde la tienes? (Dándola)

Toma.: $\quad$ iPor San Antonio, vecinos, acudid!

Franc.: $\quad$ Tráela, malvada, que a palos hoy sinó quedas tronzada.

Toma.: ¡Ay, que me matan, Virgen!

Franc.: No hay recelo.

Toma: :Vecinos, acudid!

Frane:: - Suelta ese pelo ¿Fuiste a la buena gloria?

Te ha de quedar, por Dios, ${ }^{*}$ de ella memoria. $\quad 785$

(Tomasa, en ademán de borracha)

¿Pero si está pasada, Virgen mía!

¿Que se consienta aquí esta picardîa!

(Salen dos Alcaldes de Barrio)

Alc.1: ¿Qué alboroto? ¿Qué ruido estás causando así. ¿Qué ha sucedido?

Franc: ¿Qué he de tener, señor, si este demonio de mujer que me cupo en matrimonio después de haber vendido mi pobreza, colchas, mantas y toda mi limpieza ${ }^{41}$, hasta la misma falda hoy ha empeñado? / Veisla aquí, (Muéstrala) que ha un instante me la han dado.

+1. "Limpieza": Ropa blanca, mudas. 
Se la dejó empeñada en la taberna por seis reales con que pagó la terna para ir a un barrabás de buena gloria, cuya maldad, señor, es bien notoria, de donde hecha una cuba toda viene. Mirad, señores, qué consuelo tiene un pobre que a la noche viene a casa después que el sol y frío le traspasa para ganar la vida*, y ve a su espalda que la mujer le vende hasta la falda para ir a emborracharse. ¿Habrá paciencia que pueda tolerar tal insolencia?

Alc.2: ¿Qué * respondes a esto?

Toma.: Señor, mire vusté (Como borracha)

Alc. 2:

Responde presto.

Toma.: Murió el tiu Juan Santos, que era hermano de la majuer de Quico el italiano, que es primo de una tía de mi güela por parte de mi madre la Miguela.

Alc:1: ¿Y qué tenemos con eso?

Alc.2: Está pasada. Dejadla con los diablos.

Toma: ¡Ay, no es nada!

Franc.: Ya será buena granizada la que caiga en tu culo, gran taimada. /

Alc.1: Déjala dormir el torbellino y que sienta después lo que es el pino rompiéndola los huesos a trancazos porque sinó te empeña hasta los cazos.

Franc:: Eso haré y te aseguro que la pondré su cuerpo bien maduro.

Toma.: ¡Vaya! No ti enfaes, Quico de mi vida. (Como borracha)

Franc.: Yo te aseguro estarás bien divertida y puedes, desde luego, prepararte... Vamos a casa que allí como otra parte he di quitarte el polvo a la camisa. (Vanse)

Todos: Vaya, que sido lance de gran risa./ 


\section{VARIANTES}

De no indicarse otra fuente, estas variantes proceden del MS 43.

pág. 1 "viuda"

vs. 18 "el comercio le veo muy medrado"

51 "abuso"

52 "Buenas Glorias y se halla"

70 "pensará"

71 "digno"

127 "declamado"

145 "cobertores"

147 "pescase»

150 "viéraslo"

pág. 8 «forman dos anillos»

vs. 174 «enjunto"

179 "cuatro y cinco"

188 «alcuerdu»

194 . "A dos riales" (JPL)

197 "tres"

203 «dos riales" (JPL y P)

206 "Tomasa" (JPL)

213 «juego» (JPL)

216 "cuantus»

220 "estrujada" (JPL)

224 "veintidós"

236 "guerra"

272 «nos»

288 "asperaban"

302 "Lucia. Hija, encomendarle a Dios» (JPL)

307-312 Desde "Arrecemos...» hasta «Ay probe», omitido en JPL.

310 "en güena"

321 "Susa" (JPL)

325-326 Entre estos versos: «En vuestro día glorioso / me llevasteis» (JPL)

329 "no"

363 "QQué buen»

369 "Qué amigos"

391 "por ahí (JPL)

393 «Tan bien» (JPL)

410 «bueno"

418 Los versos 418-422 faltan en MS 43.

424 "yerno"

429 "Eso yo me lo dijera"

442 "me"

450 «aparejos"

459 «Pepuca» (JPL)

463 "el maríu"

468 "mas que"

477 "Caiz"

478 "Caiz"

434 "pobrezucas"

542 «alma mal» (JPL)

544 "Puca"

573 "aguejó" 
574 "y me alcordaré jamás"

591 "estén»

603 «Búscalos»

610 "güéleme"

630 «miedo»

635 "no me doy"

658 "vengáis"

679 "con"

694 «de casa»

727 "dejarlo"

734 "Vecinos"

743 «tengo"

785 "pardiez"

791 Este verso falta en MS 43

804 "su vida"

808 «Y qué» 